\title{
Looking For The Fundamentals Of Post-Crisis Economics
}

\author{
Jan Komorowski, Warsaw School of Economics, Poland
}

\begin{abstract}
The current global crisis leads to new theoretical concepts that will go beyond neoclassical economics. The behavioral approach helps to understand business choices, autonomy, subjectivity, efficiency, etc., and finally, it goes to define such categories as business personality, goals, values, rationality, ethics, and relations in environment. The inevitable conclusion is to replace "profit maximization" with the "business development" paradigm. This article explains fundamentals of this new positive behavioral economics paradigm.
\end{abstract}

Keywords: Theory of Economics; Behavioral Economics; Theory of Enterprise; Current Global Crisis

\section{INTRODUCTION}

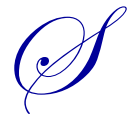

ince the crisis broke out on a worldwide scale, there is an increasing belief that we live in times which represent the end of an era. Although one may find many views that downgrade the scale of the crisis and its scope, it is certain that the crisis is an announcement of major changes and revaluations that reshape the realities of the twenty-first century, simultaneously with globalization, which is changing the consciousness of man, society, and management conditions. The complexity of this phenomenon stems from the fact that the dynamic growth in the last decades has led to growing imbalances in the spheres of production, trade, consumption, savings, and debt. This total imbalance has a distinctly geographic polarization.

Difficulties of economic recovery from this crisis are associated with restrictions that have adopted the liberal state itself, simultaneously with the state of public finances. But what drives the crisis is a confrontation of models of civilization that highlight the crisis in a social dimension that include lasting unemployment, aging populations, low fertility, consumerism, and the diversity of values.

There are clear signs that the deep economic crisis, in which the western civilization entered, is also a crisis of economic science. Contemporary economic theory has exhausted its ability to explain reality. On the basis of its accepted paradigms, it is not possible to project the future. There is no convincing vision of the future for today's generation of students whose professional activity will continue until 2060 or longer. The future of economics is therefore unknown and there are, so far, no clues as how to steer a satisfactory course out of the crisis.

Professors of economics continue to defend the old concepts that do not solve real problems. Overcoming the crisis therefore requires the discovery of a new economics to support the economy on new foundations. So it was in the past. At times of sharp downturns and world economic crises, new economic concepts were being explored.

\section{THE CRISIS OF CONTEMPORARY ECONOMY SCIENCE}

About the crisis of economics, one can say that the possibility of solving contemporary problems and predicting the future of the economy on the basis of recognized economic theories are limited. It is difficult to accept what classical economics assumes, that the market itself will restore the balance. It is known that market rationality is an illusion and the market itself is not the driving force behind change, but an abstract economic model. This model reduces complex economic processes to a mechanism of supply and demand, and it is imperative to compete with everyone. It is impossible to solve today's problems based on knowledge partly from the nineteenth century, which was created in a different era, on the basis of nascent capitalism. 
Classical economics and its numerous derivatives of concepts give a simplified picture of reality. Relations between supply and demand explain the general issues and ignore the qualitative processes, turning away from individuals' needs and behaviors, behind which hide the real business entities. This causes difficulties in predicting changes and the control of qualitative processes that are foreseeable in the economy.

From the position of individual companies, it is difficult to determine what is right or reasonable. Therefore, understanding their individual needs, interests, experiences, and opportunities requires deeper analysis than the market approach. It is worth noting that companies not only compete, but more often in contrary to the logic of conventional economics cooperate, take the interests of the community into account and interact with the environment. In this context, the desire to multiply capital in the name of the wealth of investors sounds barbaric, primitive, and anachronistic. The company is not only the investment portfolio, subject of the transaction, or a means towards a goal. There is nothing unusual in the fact that, while searching for factors determining the outcomes of enterprises, more and more often, restrictions of conventional neoclassical economics and the conventional market-based approach that uses the language of money, numbers, and symbols are being avoided; in case of violation of the rules of accepted risk, equal benefits or ethics, increasingly looking for explanations of complex economic issues in the field of psychology, culture, and organizational conditions. More appropriate is a holistic treatment of an enterprise taking into account not only its financial, but also its understated real and personal spheres of activity.

The instruments that result from Keynesian theory also seem to be exhausted, because there is no possibility of solving contemporary economic problems by administrating the economy. The state, which initially was to stimulate the development and market equilibrium, expanded the state apparatus, public services, and social needs and expectations. The economy was ignored, sacrificing economic policy by accepting stagnation and unemployment. Further expansion of the public sector has no future because the increase of public expenditure contributes to the expansion of debt, and the growth of taxes inhibits the dynamics of the economy.

The thing is that the development of the public sector is independent to the capabilities of the economy under the influence of social pressures. Aging of the population, costs of social services, medical services, public sector salaries, military activities, as well as consumerism drive the expansion of the public sector and the states' administration. All this creates pressure on the continuous growth of public spending, regardless of the ability to generate revenues by the private sector of the economy.

The share of state spending in the economy reached the limits of endurance for the economy. In most European countries the development of the public sector has outgrown the private sector. It has reached such dimensions and dynamics of growth that the possibility of inhibiting its growth seems impossible. In fact, the crisis of public finances in Greece had such a mechanism at the heart of its eruption. The threat of a next wave of the crisis is still visible in other countries. It turns out that, at the current proportions of the public sector to the private sector, the only solution to reduce the proportion of public debt and its real burden is using the method of depreciation of money initiated by the state.

Economics did not create a satisfactory theory which would take into account the global transformation. Monetarism was to be a way of stimulating sustainable economic growth in terms of openness of economies through controlling interest rates and money supply. In fact, the application of this doctrine led directly to the global financial crisis. Actually, the mechanism of the financial crisis was launched by the abuse of monetary policy instruments, as a result of oversupply of the dollar in the global economy and very low interest rates, aimed at funding the gigantic U.S. public debt. For these reasons, the neo-liberal doctrine of monetarism is experiencing a decline, has lost all its vitality and, in fact, became a direct source of the current problems. Issuance of treasury securities, and further expansion of public debt at a frightening rate, is not evidence that monetarist doctrine is still being utilized but is an expression of helplessness and lack of ideas on the way to overcome the crisis.

Criticism of the following economic concepts contributed to the so-called mainstream economics which includes what is common to neoclassical and Keynesian economics. But this does not create a new quality, but is a conglomeration of knowledge for the purpose of education which resembles an eclectic construction built on old and shallow foundations. The market became the fetish instrument for this structure, being regarded as a self-regulating 
system that assumes that everyone will compete with everybody. The multiplication of profits for the shareholders became the primary objective of a company. The philosophical category of value was reduced to economic value, the managing of the company to managing its finances, the process of development to the process of investing, and the entire economy to the market relationship. At the same time the developments in other disciplines of science are being ignored; i.e. the importance of technological progress, multiculturalism, civic participation, environmental problems and limited resources. Hence the well-known economic theories become less and less useful in explaining the economic reality.

This, a kind of reductionism in modern economics, simplifies the complexity of economic phenomena and the cognitive capabilities. The science of economics is completely disoriented. We must be aware of the fact that, on the grounds of the economics being in the condition of profound change, it is difficult to determine the direction in which the improvement of the functioning of an economy should develop to revive economic growth.

Therefore, the development of modern economics is clearly evolving towards an interdisciplinary approach involving integration with other social sciences. The company and its relationship with the environment are in fact the matter of a social nature.

\section{BEHAVIORISM BEING A WAY OUT OF THE TRADITIONAL FRAMEWORK OF ECONOMICS}

The problem of rationality is the key concept in economics and the subject of an ongoing dispute. It is located at the center of interest within academia, because what is rational or beneficial at the level of the decisionmaker has to translate into economic efficiency of the economy. Attempts to find the relationship between theoretical concepts in economic literature and the real world ended with varying degrees of success. Indeed, the concept of homo economicus, demonstrating the optimal choices of individuals is an obvious simplification that deviates from the realities of life. The established type of economic man, as attributed to the Father of economics Adam Smith, regarded as the embodiment of optimization, in essence boils down to choices based on selfishness, the pursuit of maximizing individual benefits without any restrictions. Rationality limited to economic calculation is not enough to understand the choices made.

Further work towards constructing arguments that optimize the choices of the decision-makers went in the direction of analyzing the impact of limited information and risk. In neoclassical economics," rational "means making choices that are in accordance with a set of preferences which produce the ideal result for the decisionmaker and are not necessarily impacted by certain peripheral considerations such as the costs of access to information. Neo-classical economics clarifies this approach of rationality, stating that if there is uncertainty as to future results of operations; rationality means maximizing expected utility, which is obtained by multiplying this utility by the likelihood of its occurrence.

Significant development of behavioral concepts occurred in the second half of the nineties. Behavioral economic concepts are formed under the influence of the development of social sciences, including sociology, psychology, psychiatry, ergonomics, as well as ethics, history, political science, and other disciplines. Knowledge of human behavior in organizations is also based on the use of demographic analysis, statistical methods, and even the natural and biological discoveries concerning the brain and nervous system. As a consequence, the behavioral approach collides with the social nature of a man within the sphere of economic relations by enriching the views of the mechanism of choice making, decision-making, and management effectiveness.

Interests in behaviorism are directly linked to some kind of dawning of quantitative methods in economics which flourished under the influence of the development of econometric methods, programming, technical analysis, risk evaluation, information technology, and computer science. Under the influence of these factors, the analytical engine of quantitative analysis has developed so far that, being limited by the boundaries of quantitative methods, further development does not significantly increase its cognitive abilities.

In the development of behavioral economics, the formation of various trends can be observed. Initially, attention was paid to cases of behavior that were in contrary to the efficiency of economic calculation by treating them as irrational behavior. They were to confirm the validity of the traditional economy and led to the development 
of utilitarian knowledge under the influence of various discoveries and practical solutions. Behavioral concepts for the capital market and investors on the stock market can be given as an example.

As part of this trend, a big emphasis is given to psychological interpretation of so-called market anomalies and other kinds of behaviors of investors classified as irrational, enacted under the influence of cognitive distortions, emotions (grief, fear, sentimentality, self-confidence), experiences, mental accounting, intuition, personal attributes, etc. As part of this trend, various detached concepts of repeatable empirical phenomena are being developed; i.e. phenomena and formations of a market in certain circumstances, such as the "speculative bubble effect," "the effect of predisposition," "sunk cost trap," "calendar effect," "anchor effect," "paradox of closed funds," etc. Their detection and possible application in financial engineering to manipulate the financial markets and for speculative purposes is a derivative of a specialized knowledge and experience of experts and practitioners of management who well know the behavior of players on individual markets.

Under the influence of application of psychology in economic analysis, the subjective element in the approach to rationality has been highlighted. After all, what is doubtful and uncertain in the economic reality and abstract economic models can be sometimes explained in the context of motives of human behavior and social relations. Most of all, next to the axiological dimension of the decision and the changing ethical demands, it is not possible to determine what is rational without taking the autonomous decision-maker into account. Rationality, therefore, is not only a matter of economic calculation, but also that of experiences and values of the objective and subjective perceptions of reality and limited cognitive capabilities.

The emergence of the general framework of behavioral economics forms a wide-ranging area for the interpretation of economic relations, with the use of knowledge in the field of psychology, sociology, philosophy, and culture. Nevertheless, economics is an open social science, not only a set of quantitative models. It seems that the development of the new economy is moving towards the positive, general theory of behavioral economics, based on original assumptions, which, as can be expected, will set the main directions for the development of economics in the coming decades of the twenty-first century.

Although future developments are quite uncertain from today's perspective, on the basis of the foundations of this trend of thinking, it can be assessed that the natural barrier to the development of behavioral economics would be the application of artificial intelligence for managing complex business processes at diverse levels. Actually, thanks to integrated computer programs, there exists the possibility to control and coordinate activities on a global scale, collect information about executed transactions and movement of resources, and also monitor the revenue and expenditure and to calculate tax liabilities via an online system. All this creates new opportunities to optimize business processes in a number of different ways.

It is worth mentioning that having the presented characteristics of behavioral economics, it is difficult to talk about a coherent and systematic knowledge at this stage. This involves, inter alia:

1. lack of general acceptance by the academic environment of the scope and systematics of behavioral economics that corresponds to the criteria of the scientific discipline,

2. lack of a system of paradigms, axioms and theorems,

3. lack of systematic conceptual apparatus, which means the ambiguity of understanding of economic categories, such as optimization, rationality, effectiveness, value, etc.

4. numerous borrowings of methods and research tools from other disciplines.

At this stage, all this may suggest a specific research approach is being applied rather than the existence of a universally accepted, tested method and interpretation, which would define a new form of economic knowledge. It appears that all the above is still in the early stages of development. But it is possible to extract what is distinctive and common in the behavioral approach in economics, and these are:

1. Subjective approach to decision-makers that assumes the possibility of them learning, leaving them with a broad sphere of freedom and autonomy of choice, in contrast to the determinism of classical economics. 
2. Examination of choices as subjective decisions of independent entities; i.e. individuals, businesses, states, and other isolated groups of individuals, determined not only economically but also psychologically and sociologically.

3. Explanation of economic relations not being based on more or less sophisticated theoretical models, but on the analysis of individual cases, that take into the account the subjective relations, individual behavior, and group relations.

4. The possibility of interdisciplinary study/analysis in a comprehensive manner, using all available knowledge, expertise and advanced methodologies, including multi-criteria analysis methods, qualitative quantitative, dynamic, experimental, etc., therefore a much richer skill-set than in the traditional economy, based mainly on a study of quantitative dependencies.

5. Formulation of problems, hypotheses, and questions in a way that assumes a systematic approach to the examined economic phenomena, taking their complexity and dynamics of condition internally and externally into account, that are under the influence of dynamic structures based on the relation of economic and human relations.

6. Finding solutions oriented on the creation of development potential, cooperation, and synergy, therefore, more efficient solutions compared to the market mechanism of resource allocation within the framework of traditional economics.

In the context of the behavioral approach, which is more widely accepted in management, finance, and the theory of enterprise, questions about the relationship of this trend with the traditional approach to economic science are being formulated. During dynamic changes, qualitative new financial problems occur, for which traditional economics is prone to be deterministic and inflexible. The pace at which the world economy is growing, especially the financial markets, outperforms the development of scientific thought over these processes. This means that the decision-makers/policymakers are under-equipped with adequate knowledge and yet are under pressure from the expectations of their constituents, without having a clear assessment of their decisions. The pressure to come up with new paradigms becomes a compelling task for science.

By observation, the analysis and generalization of real relationships searches for new patterns and approaches that act as paradigms which underpin the creation of new concepts and theories that explain the changes in a better way. Adoption of a particular paradigm integrates science and sets out guidelines for its development. There are two essential aspects, descriptive and prescriptive, that specify the order of things in a particular field and indicate the methodological framework for solving the problems that the science faces.

In the field of economic science, as well as in the discipline of finance, there are various paradigms related to the whole scientific knowledge, or only its parts. The evolution of solutions that optimize economic issues in a normative and structural-functional way is being observed, in relation to the interpretative approaches to subjective factors, including social and humanistic content. An interdisciplinary approach is aimed on the integration of scientific knowledge and the subordination of its universal values which is to serve scientific understanding.

Regarding the discussion about the paradigms of modern economics, the arguments put forward by Prof. Ryszard Szewczyk should be considered. The author stresses the inadequacy of the transfer of methods from natural science to the grounds of social sciences that ignore awareness of decision-makers, which means that the knowledge of the mechanics and the position assessment of corporations allow one to determine where the entity will be in the future. He argues that all human behavior is not only subject to its mere existence but also to its development, as a constant improvement to its quality of life. Humans desire to improve the quality of their life, their community, which also develops when "...the improvement of quality of life progresses, for even one of its members, without compromising the quality of others." ${ }^{1}$

From the presented discussion it concludes that the economics of the future set to initiate the processes of sustainable development will be followed by synthesis of interdisciplinary knowledge and search for positive solutions by combining the factors of an economic, sociological, and also psychological nature. It will be required to

\footnotetext{
${ }^{1}$ Szewczyk R. (2010). W sprawie fundamentu teorii finansów, in : Ku nowemu paradygmatowi nauk o finansach, Red. W. Frąckowiak, J. Szambelańczyk, Poznan, Wydawnictwo Naukowe Uniwersytetu Ekonomicznego w Poznaniu, Poznań, pp. 25-26.
} 
use all available scientific knowledge, derived social and natural science, in the solving of economic issues which is a condition of getting closer to knowing "the truth." From the perspective of a professional research approach, the conventional knowledge, based on simplifying assumptions and ignoring other scientific disciplines, is being lost.

\section{THE CONSEQUENCES OF A SUBJECTIVE APPROACH TO AN ENTERPRISE IN THE NEW ECONOMICS}

Without going into detailed analysis of the comparative competiveness of the Far Eastern economies and those of the Western World, it can be assumed that economic development in the XXI century will be determined by the evolution of the modern enterprise. The concept of the New Economics for post crisis times is urgently needed. This allows the following assumptions concerning positive behavioural economics to be formulated:

First, the starting point is to place at the centre of attention, the subjectivity of an enterprise as a consequence of its human and social nature. Any enterprise, whether it be an individual or a collective entrepreneurship organized in corporate form, acts through its people and therefore cannot be treated objectively.

Second, in building economic relations with other business entities, we are looking for the answer as to whom we should be dealing and how we should share added value amongst the participants of these dealings. So, how others judge us becomes an important consideration, whereas traditional economics interprets facts and features impersonally. In fact, profits division among groups of interests within the business unit is a common practice. Therefore, in making choices regarding relationships with other entities, self-interest and selfish decisions are not deemed to be destructive where cooperation in business is concerned. Self-limitation of enterprises, sharing gains amongst groups of interested parties and the avoidance of harm to others become a necessity. Consequently, a fundamental requirement of business in a particular economic environment is one of acting in an ethical manner.

It is worth emphasizing that it is not just the notion of self-valuation, or any form of unilateral declaration of those entities that they operate ethically as being satisfactory, but that their credibility in their operational environment should be upheld. Without this credibility, it is not possible to build a lasting economic relationship since it is this that forms the basis for gaining trust. Thus, in addition to the economic calculation, it is the ethical dimension of economic activity that becomes the key criterion in determining valuation.

Third, the essence of subjectivity is a function of possessed freedom, including the freedom of economic activity and autonomy in making choices freely, which is the superior value for all entities. This sense of freedom determines the identity of the entities because the curtailment of freedom inhibits entrepreneurship, impacts upon the finding of optimal solutions, reduces gains, and ultimately leads to enslavement. ${ }^{2}$

Fourth, if economic freedom is the principal value for all subjects, then the main objective of independent business entities must be the search for the development and fulfillment of the mission (self-realization). Hence, the choice of corporate goals is a consequence of A. Maslow's pyramid of needs. Then, generating profits for the owners of capital can be regarded only as the need to incur the cost of using capital, and not the primary objective.

Fifth, enterprises as individual entities operate in their own particular environment. The concept of the business environment is more wide-ranging than that of the concept of the market, the latter reducing the actions of the companies merely to the relationship between supply and demand, which is an oversimplification. The business environment contains within it all issues associated with the market, but also encompasses the roots of entrepreneurship together with geographical, social, and cultural factors of development, which business units must take into account. These are not all included within an analysis of the marketplace in isolation.

In this way, the concept of the business environment breaks the paradigm of competition of all against all, and allows a choice over the option of cooperation between entities for co-development. From an analytical perspective, it allows the replacement of business models based on the maximization of profit by more complex

\footnotetext{
${ }^{2}$ In fact, real socialism collapsed not because of the lack of a market which is an abstract concept, but because of restrictions on economic freedom.
} 
models involving multi-criteria optimization, focused not only on the interests of shareholders, but also taking into account other groups of interests.

Six, the functioning of business entities should be considered integrally and multi-dimensionally and not only in financial terms. One of the causes of the recent economic crisis was the exclusive focus of companies on the financial dimension of business. In this way, business performance became a function of virtual processes aimed primarily at the creation of profit and involving casino-like speculation on the capital markets. Ignorance of the real purpose of business becomes a reason for selfish competition and technological decline, leading to a lack of genuine business vigour and a regression in the proper application of human capital.

A positive behavioural approach enriches the economic analysis of any business entities' subjectivity and introduces a dynamic ethical dimension into the decision-making process within the business environment and associated realisable values, etc. This leads to the conclusion that the factors affecting performance and development of an enterprise are ultimately related to its organizational culture, including its internal relations and the pervading culture of the general business environment in which it operates.

\section{SUMMARY}

First, the mechanical approach of traditional economics, focusing on the financial objectives of entities to maximise individual benefits, in practice contributes to the causes of macroeconomic imbalance, conflicts of interests, low levels of innovation, as well as the 12 alienation of the workface. As a result, in the largest economies of the Western World, on the one hand we observe the expansion of the financial sector and on the other, economic decline, deterioration in productivity, the loss of competitiveness, the disappearance of many industries and negative growth. These are not the only manifestations of the crisis, but the effects of the postulates of traditional economics as relating to the domination of financial markets, the attitude of a quick profit, cost-shifting, insufficient investments, and ignorance of the non-financial aspects of management.

Second, the behavioural method directs its attention to the issue of the subjectivity of an enterprise. In contrast to traditional economics, concentrating on the market, in the New Economics, which integrates knowledge from various different disciplines, the references will be directed at the specific business entity which is then treated as an individual subject within its own specific business environment. The behavioural approach draws attention to the identity of an entity, its internal qualities, intellectual potential, suitability, reliability, goals, and values, which it performs in the financial, personal, and real economy. Everything that builds relations based on trust and reliability in the environment creates ethical requirements and advances the understanding of rationality and optimisation.

Third, since the fundamental value of independent enterprises is economic freedom, the natural imperative of their activity is to strive for development and self-realisation. Hence, there exist a number of arguments for changing the concept of maximising value and the creation of shareholders' wealth as the primary objective, to the striving for tangible positive development. If an entity is considered independent, intelligent, well-organised, and professionally managed, its prospects should be determined by its goals and values, which then become its main drivers. Therefore, managing human capital refers to the application of such values as: reliability, responsibility, cooperation, trust, social order, etc., as factors which increase the economic efficiency of an enterprise and its position in the business environment.

Fourth, an enterprise must be assessed not only in terms of its capabilities to create wealth for the owners of its capital. Since economic activity is dependent on the human element, the route to improving performance and expanding economic value is to create development opportunities for the employees. Therefore, the economic value of the company is determined by its aspirations, technological advancement, modernity, and the attractiveness of its products/services. In this area there are also causes of failure, lost profits, missed opportunities and the alienation of workers. In this way, human capital, internal culture, and willingness to cooperate translate into improved financial results.

Behaviourism examines the impact of humans on economic choices and this requires an analysis of the economic relations of an enterprise through the prism of axiology, culture, and human values. Such an extension of 
the methodology of economic analysis in relation to traditional economics enhances cognitive and other applicable opportunities. In this way, the New Economics, as a synthesis of economic calculation and business ethics, based on a new approach to business entities and assuming redefinition of rationality, expands the research capabilities relating to economic problems and also the most recent economic crisis.

Theoretical issues, seen in the light of the assumptions of the New Economics are also of interest to the philosophically-minded person. The common area of research for both disciplines appears very promising in the search for answers to the following questions: how best to implement the humanistic postulate of placing man before work and how best to nurture positive economic relationships with other business entities. It can therefore be assumed that the New Economics will be more humanised, based on human values, subordinated to the needs, abilities, and aspirations of modern man's development. ${ }^{3}$

\section{AUTHOR INFORMATION}

Jan Komorowski is a professor at Warsaw School of Economics and is the Chair of Finance, with many years' experience as a top executive in shipyards, electronics, retail, and consulting corporations. He studied at the University of Gdansk, LSE, JICA Japan, and University of Frankfurt, ESC Rouen, NEIU Chicago, and others. He has published over 50 articles and the books: Budgeting as the Method of Corporate Management (97), Financial Planning in Corporation (2002), Goals and Values of Contemporary Enterprise. Behavioral Approach (2011), and Goals of Enterprise and Development of Economy (2012). He promoted 12 doctorates. E-mail: jan.p.komorowski@gmail.com

\section{REFERENCES}

1. Czerwonka, M., \& Gorlewski, R. (2008). Behavioural finance. Warsaw: SGH Publishers.

2. Haugen, R. A. (1999). New discipline of finance. Warsaw: WIG-Press.

3. Komorowski, J. (2011). Goals and values of contemporary enterprise, behavioural approach. Warsaw: SGH Publishers.

4. Komorowski, J. (2005). Credibility of enterprise as an economic value. In Studies of management and finance (nr 54). Warsaw: SGH.

5. Szymański, W. (2009). The global crisis, the first approach. Warsaw: Difin.

${ }^{3}$ The article refers to the book by J. Komorowski, Goals and values of contemporary Enterprise. Behavioural Approach. SGH Publishers,
Warsaw 2011. 